\title{
Research and Application of Fluorine Complex Acid Plug Removal and Sand Consolidation Agent
}

\author{
Zhanshuang XU \\ Drilling and Producing Technology Research Institute, Liaohe Oilfield, Panjin, 124010,China \\ Email: xuzs@petrochina.com.cn
}

Keywords: Fluorine Complex Acid; Plug Removal And Sand Consolidation; Reaction Mechanism; Field Application

\begin{abstract}
Fluorine complex acid plug removal and sand consolidation agent is composed of trifluoroacetic acid, corrosion inhibitor, complexing agent, surface active agent. In this paper, the reaction mechanism, clay dissolution quantity, change of formation permeability, resistance to erosion intensity of fluorine complex acid plug removal and sand consolidation agent were studied, the experimental results showed that the fluorine complex acid plug removal and sand consolidation agent agent can not only relieve the mud pollution, but also firm sand when enhance the permeability. This new agent will be applied to the mud plugging and fine sand wells.
\end{abstract}

\section{Introduction}

During the process of window sidetracked hole of low pressure heavy oil block of Liaohe Oilfield, a large amount of alkaline mud in near wellbore zone emulsify with heavy oil when the well completion production[1]. When open well production, thin oil wells shut down because of the mud and powder sand output or reservoir drainage difficulty caused by strata equilibrium conditions change in high clay content stratum[2]. These two blocks will cause stuck pump and frequent workover or shut.

In view of the above situation,a fluorine complex acid plug removal and sand consolidation agent has been developed, and the mechanism, clay dissolution rate, permeability and core anti erosion ability also been studied. The agent can dissolve clay and generate vitreous nano coating which can mix the remaining clay and fine silt particles together as the shape of skeleton ,so as to realize plug removal and sand consolidation integration.

\section{Plug removal and sand consolidation mechanism}

Trifluoro acetic acid and borax reaction generated fluorine complex acid, which can slow hydrolysis generated complexing anions under formation conditions, and release $\mathrm{H}^{+}$, $\mathrm{F}^{-}$which up to $3 \mathrm{H}^{+}, 2 \mathrm{~F}^{-}$, this is a triple ionization of acids. It is suitable for oil deep processing because its dissolution capacity is stronger than mud acid, and also has slow response speed. The reaction equation as follows:

$$
\begin{aligned}
& \mathrm{F}_{3} \mathrm{C}_{2} \mathrm{OOH}+\mathrm{Na}_{2} \mathrm{~B}_{4} \mathrm{O}_{7}+\mathrm{H}_{2} \mathrm{O} \rightarrow(\mathrm{OH})_{3} \mathrm{~B} \cdot \mathrm{F}_{3} \mathrm{C}_{2} \mathrm{OOH} \\
& (\mathrm{OH})_{3} \mathrm{~B} \cdot \mathrm{F}_{3} \mathrm{C}_{2} \mathrm{OOH} \rightarrow(\mathrm{OH})_{3} \mathrm{~B} \cdot \mathrm{F}_{3} \mathrm{C}_{2} \mathrm{OO}+\mathrm{H}^{+} \\
& (\mathrm{OH})_{3} \mathrm{~B} \cdot \mathrm{F}_{3} \mathrm{C}_{2} \mathrm{OO}+\mathrm{H}_{2} \mathrm{O} \rightarrow(\mathrm{OH})_{4} \mathrm{~B} \cdot \mathrm{F}_{2} \mathrm{C}_{2} \mathrm{OO}+\mathrm{H}^{+}+\mathrm{F}^{-} \\
& (\mathrm{OH})_{4} \mathrm{~B} \cdot \mathrm{F}_{2} \mathrm{C}_{2} \mathrm{OO}+\mathrm{H}_{2} \mathrm{O} \rightarrow(\mathrm{OH})_{5} \mathrm{~B} \cdot \mathrm{FC}_{2} \mathrm{OO}^{-}+\mathrm{H}^{+}+\mathrm{F}^{-}
\end{aligned}
$$

Hydrolysis of fluorine complex acid generate $\mathrm{H}^{+}$and $\mathrm{F}$ - which can dissolved components of bentonite and stratum. The reaction equation as follows:

$$
\begin{aligned}
& \mathrm{Al}_{2} \mathrm{Si}_{4} \mathrm{O}_{16}(\mathrm{OH})_{2}+\mathrm{H}^{+}+\mathrm{F}^{-} \rightarrow \mathrm{H}_{2} \mathrm{SiF}_{6}+\mathrm{AlF}_{3}+\mathrm{H}_{2} \mathrm{O} \\
& \mathrm{CaAl}_{2} \mathrm{SiO}_{8}+\mathrm{H}^{+}+\mathrm{F}^{-} \rightarrow \mathrm{AlF}_{3}+\mathrm{CaF}_{2}+\mathrm{SiF}_{4}+\mathrm{H}_{2} \mathrm{O} \\
& \mathrm{SiO}_{2}+\mathrm{H}^{+}+\mathrm{F}^{-} \rightarrow \mathrm{SiF}_{4}+\mathrm{H}_{2} \mathrm{O}
\end{aligned}
$$

Because the dissolution of bentonite ,argillaceous and a small amount of silica sand, the formation permeability increases. $(\mathrm{OH})_{4} \mathrm{~B} \cdot \mathrm{F}_{2} \mathrm{C}_{2} \mathrm{OO}^{-}$and $(\mathrm{OH})_{5} \mathrm{~B} \cdot \mathrm{FC}_{2} \mathrm{OO}^{-}$generated by the hydrolysis of complex can react with residual clay and compress the clay to be lamellar which can 
adsorb on the surface of the sand. In addition they also can react with the surface of quartz and generate a coating of crystalloid fluorine boron[3]. The coating thickness is only in the nanometer range, and the porosity and permeability of the reservoir will not lower than before.

In summary, fluorine complex acid can dissolve clay, argillaceous and fine quartz effectively, and can improve the permeability and also can form sandstone skeleton which can coat residual clay and make it in the reservoir stability.

\section{The effect of bentonite}

$5 \mathrm{~g}$ of level II bentonite were immersed in the following two solution, Solution A contains $12 \%$ $\mathrm{HCl}$ and $3 \% \mathrm{HF}$, Solution $\mathrm{B}$ contains $10 \%(\mathrm{OH})_{3} \mathrm{~B} \cdot \mathrm{F}_{3} \mathrm{C}_{2} \mathrm{OOH}$ solution. Reacting under the condition of $60{ }^{\circ} \mathrm{C}$ for $24 \mathrm{~h}$, then washing with distilled water and drying. The result of analyzing with X-ray diffraction is shown in figure 1.

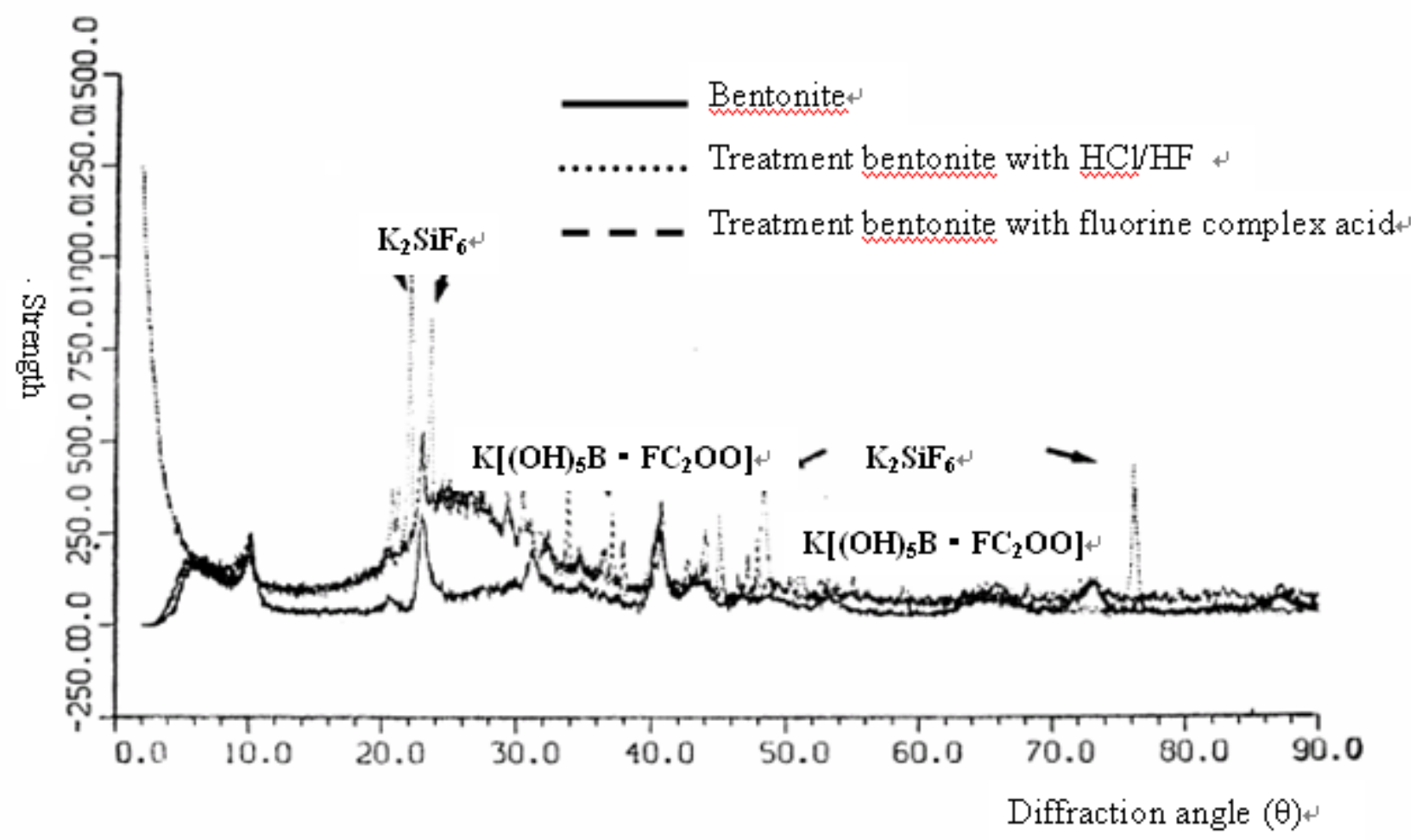

Fig.1. The result of analyzing with $\mathrm{X}$-ray diffraction

Bentonite react with $12 \% \mathrm{HCl} / 3 \% \mathrm{HF}$ to generate $\mathrm{K}_{2} \mathrm{SiF}_{6}$ precipitate. The upheaval of the peak shows that the high content of the new compound. $\mathrm{K}_{2} \mathrm{SiF}_{6}$ has large crystal size so it can not dissolve in water, this is a major factor of secondary pollution in treatment process of mud acid.

Bentonite react with $10 \%(\mathrm{OH})_{3} \mathrm{~B} \cdot \mathrm{F}_{3} \mathrm{C}_{2} \mathrm{OOH}$ to generate $\mathrm{K}\left[(\mathrm{OH})_{5} \mathrm{~B} \cdot \mathrm{FC}{ }_{2} \mathrm{OO}\right]$. From the small peak can know the content of $\mathrm{K}\left[(\mathrm{OH})_{5} \mathrm{~B} \cdot \mathrm{FC}_{2} \mathrm{OO}\right]$ is small. Further with scanning electron microscope (SEM) know bentonite crystalline of $\mathrm{K}\left[(\mathrm{OH})_{5} \mathrm{~B} \cdot \mathrm{FC}_{2} \mathrm{OO}\right]$ is coated with nano coating[4]. So it not only won't produce secondary pollution, but also has very important effect on stability of clay and formation of the sandstone framework.

By quantitative determination can know that the bentonite dissolution ability of $10 \%$ $(\mathrm{OH})_{3} \mathrm{~B} \cdot \mathrm{F}_{3} \mathrm{C}_{2} \mathrm{OOH}$ is $1000 \mathrm{mg} / 100 \mathrm{~mL}$ which greater than $870 \mathrm{mg} / 100 \mathrm{ml}$ of soil acid. 


\section{Analysis of core treatment with fluorine complex acid}

Experiment of core selection. By cold block 43 core group remove type I and II core, type II core than I core, potassium feldspar, original liquid phase permeabilities for $80 \mathrm{x} 10-3 \mathrm{~g} \mathrm{~m} 2$. The analysis of core components in Table 1 by XRD.

Remove type I and II core from Leng 43 block core group. Type II core has higher content of potash feldspar than type I core. The original liquid phase permeabilities is $80 \times 10^{-3} \mu \mathrm{m}^{2}$. The XDR analysis results of core components is shown in Table 1.

Tab.1. Petrophysical and chemical properties of two kinds of sandstone

\begin{tabular}{|c|c|c|c|}
\hline $\begin{array}{c}\text { Mineral } \\
\text { (weight percentage) }\end{array}$ & Component & Type I sandstone & Type II sandstone \\
\hline+ & & $85-90$ & $70-90$ \\
\hline feldapar & Microcline & $3-7$ & $5-15$ \\
\hline \multirow{2}{*}{ Maria glass } & Muscovite & 1 & Tiny \\
\hline & Chlorite & Tiny & 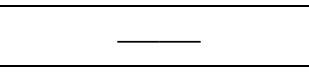 \\
\hline Carbonate & Dolimite & $2-5$ & Tiny \\
\hline \multirow{5}{*}{ Clay } & Kaolinite & $1-3$ & - \\
\hline & Glimmerton & - & $5-10$ \\
\hline & $\begin{array}{c}\text { Glimmerton + } \\
\text { Mixing layer clay }\end{array}$ & $1-3$ & $\longrightarrow$ \\
\hline & Iron pyrite & Tiny & - \\
\hline & $\begin{array}{c}\text { Iron oxide and } \\
\text { Hydroxide }\end{array}$ & - & $1-2$ \\
\hline Porosity(\%) & & 21.7 & $17-18$ \\
\hline \multirow{2}{*}{ Solubility(\%) } & 15\%hcl & 7.5 & 4.3 \\
\hline & 12\%hcl/3\%HF & 22.5 & 31.2 \\
\hline Fe dissolved in $\mathrm{HCl}$ & & 0.07 & 1.0 \\
\hline
\end{tabular}

$\mathrm{K}_{2} \mathrm{SiF}_{6}$ generated test and observation after treated core with $12 \% \mathrm{HCl} / 3 \% \mathrm{HF}$. Type II sandstone is selected for experiment for its higher potash feldspar content to be easy testied. Core specifications is $8.0 \times 2.5 \mathrm{~cm}$, first washed with $15 \%$ hydrochloric acid about 10 times of the pore volume, until the core permeability reached stable. Then injected $12 \% \mathrm{HCl} / 3 \% \mathrm{HF}$ acid of 10 to 15 times pore volume into the core with flow rate of $2 \mathrm{ml} / \mathrm{min}$, acid liquid residence time is 10 minutes, the test temperature is $60^{\circ} \mathrm{C}$. Analyse $\mathrm{Si}, \mathrm{Al}, \mathrm{K}$ and $\mathrm{F}^{-}$of effluent during the test, the result is shown in Figure 2. 


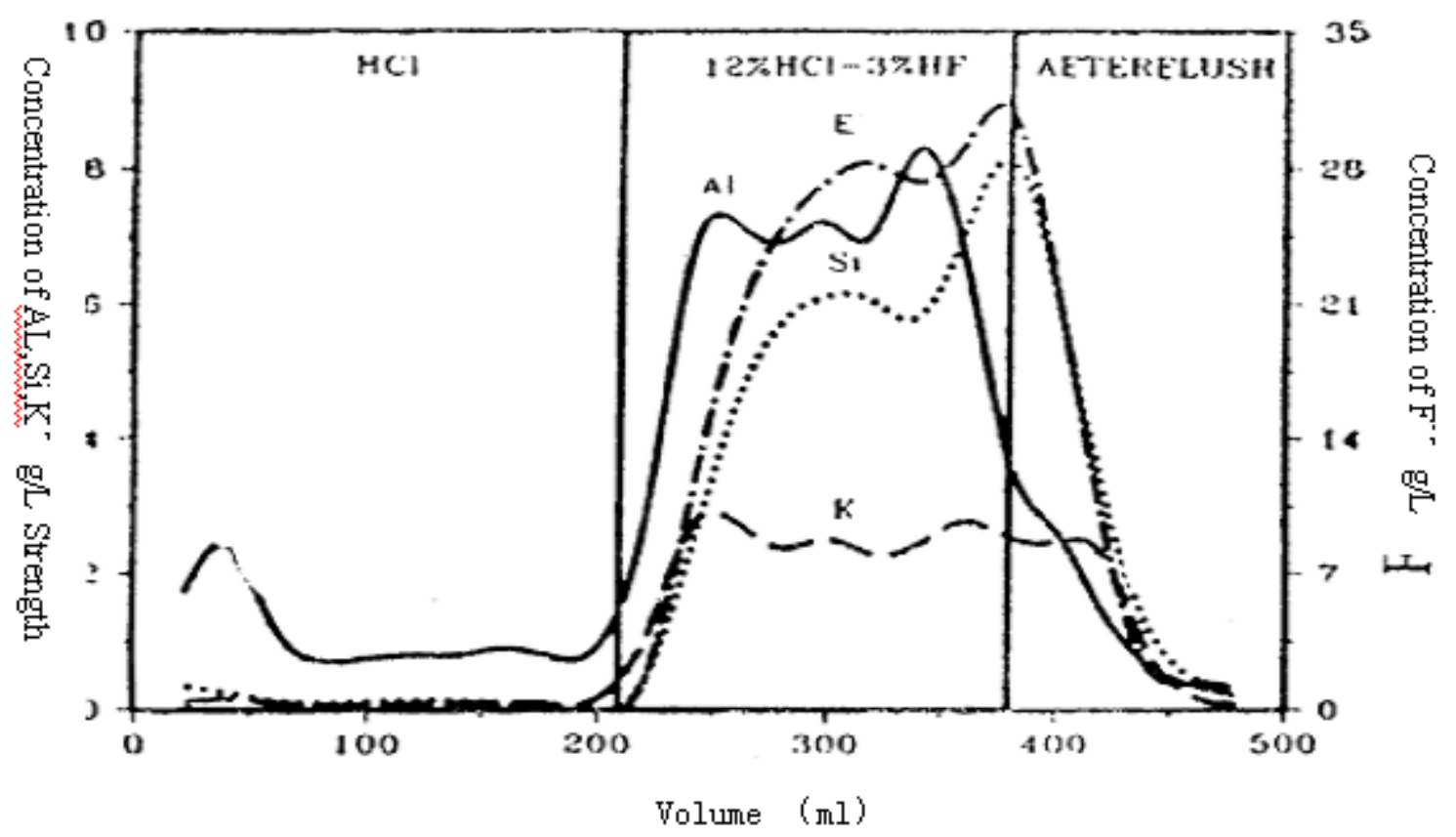

Fig.2. Effluent analysis of type II sandstone treated by $12 \% \mathrm{HCl} / 3 \% \mathrm{HF}$

From the curve can know that content of $\mathrm{Si}$ is lower than $\mathrm{Al}$, it means the consumption of $\mathrm{Si}$, and change way of fluoride is similar to that of $\mathrm{Si}$. The content of $\mathrm{Si}, \mathrm{Al}, \mathrm{K}$ in the outflow has the same tendency of the contents change in the whole flow test, and there is a suddenly-lowering when injection fluids is $350 \mathrm{ml}$, this is owing to the saturation state of $\mathrm{Si}, \mathrm{Al}, \mathrm{K}$ and the secondary precipitate of $\mathrm{K}_{2} \mathrm{SiF}_{6}$ in core. In addition, there are a large amount of sediment clogging pipes in the exit of core during the process of injection of $12 \% \mathrm{HCl} / 3 \% \mathrm{HF}$ acid. X-ray diffraction analysis confirmed that sediment is $\mathrm{K}_{2} \mathrm{SiF}_{6}$, this is because the outlet pipe temperature is lower than the temperature of the core. From Figure 2 can know that the content of $\mathrm{Si}, \mathrm{Al}$, $\mathrm{K}$ has a suddenly-lowering when cleaning fluid is between 400 to $500 \mathrm{ml}$.

$\mathrm{K}\left[(\mathrm{OH})_{5} \mathrm{~B} \cdot \mathrm{FC}_{2} \mathrm{OO}\right]$ micro crystal growth test and observation after treated core with $\mathbf{O H})_{3} \mathbf{B} \cdot \mathbf{F}_{3} \mathbf{C}_{2} \mathbf{O O H}$. Also take Type II sandstone for experiment. Core specifications is $8.0 x 2.5 \mathrm{~cm}$, first washed with $15 \%$ hydrochloric acid about 10 times of the pore volume, until the core permeability reached stable. Then injected $10 \%(\mathrm{OH})_{3} \mathrm{~B} \cdot \mathrm{F}_{3} \mathrm{C}_{2} \mathrm{OOH}$ acid of 10 to 15 times pore volume into the core with flow rate of $2 \mathrm{ml} / \mathrm{min}$, acid liquid residence time is 10 minutes, the test temperature is $60^{\circ} \mathrm{C}$. Analyse $\mathrm{Si}, \mathrm{Al}, \mathrm{K}$ and $\mathrm{F}^{-}$of effluent and $(\mathrm{OH})_{5} \mathrm{~B}^{\mathrm{F}} \mathrm{FC}_{2} \mathrm{OO}^{-}$during the test, the result is shown in Figure 3. 


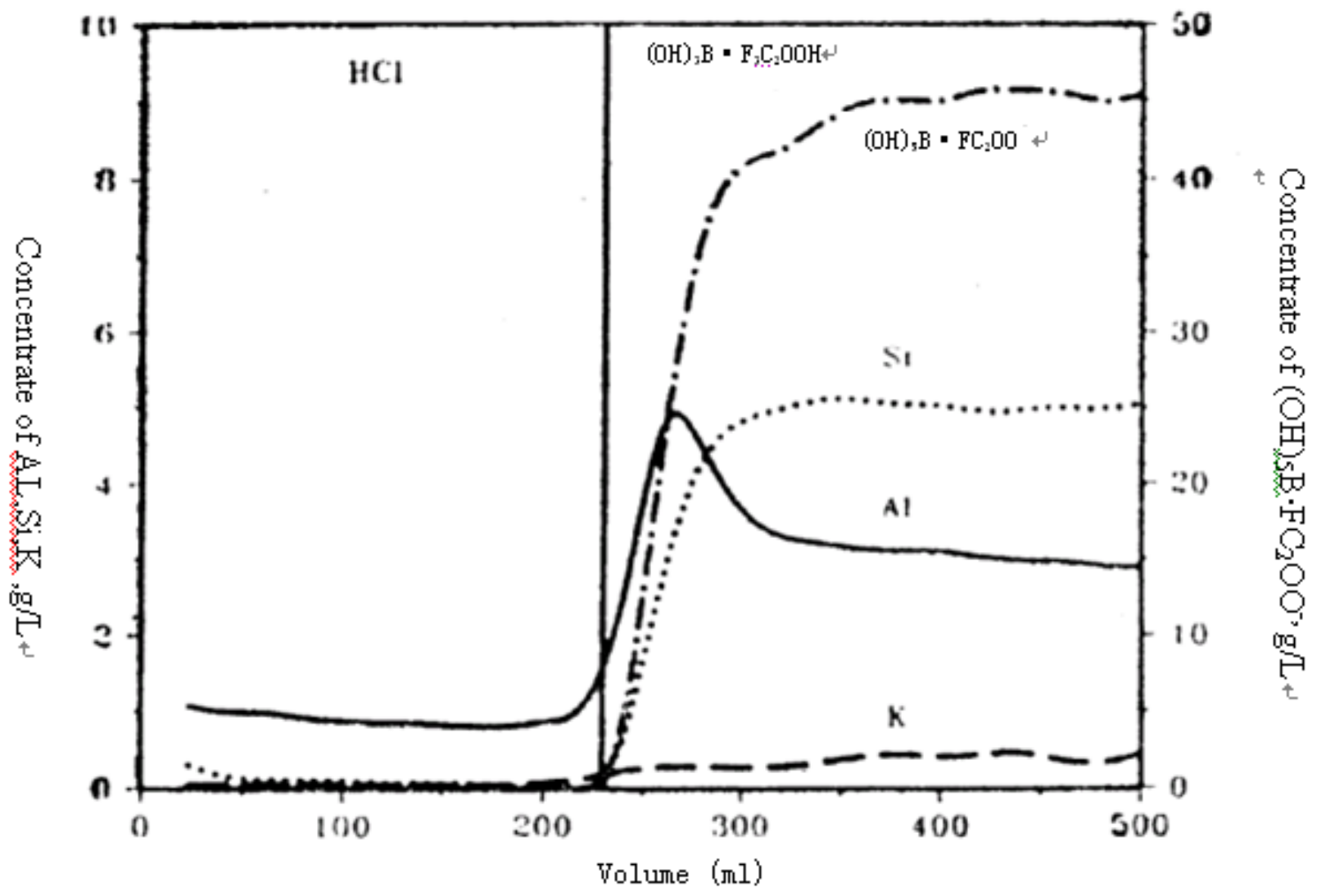

Fig.3. Effluent analysis of type II sandstone treated by $10 \%(\mathrm{OH})_{3} \mathrm{~B} \cdot \mathrm{F}_{3} \mathrm{C}_{2} \mathrm{OOH}$

After pumping $(\mathrm{OH})_{3} \mathrm{~B} \cdot \mathrm{F}_{3} \mathrm{C}_{2} \mathrm{OOH}$ acid into the core, there is only a very small amount of crystal in the outlet of core. From X-ray diffraction analysis can know the crystal is $\mathrm{K}\left[(\mathrm{OH})_{5} \mathrm{~B} \cdot \mathrm{FC}{ }_{2} \mathrm{OO}\right]$. Content of $\mathrm{Si}$ higher than the content of $\mathrm{Al}$ in the effluent curves, and the content curves of $\mathrm{Si}$ 、 $\left[(\mathrm{OH})_{5} \mathrm{~B} \cdot \mathrm{FC}_{2} \mathrm{OO}\right]^{-} 、 \mathrm{~K}^{+}$is very flat, that means there is only a very small amount of $\mathrm{K}\left[(\mathrm{OH})_{5} \mathrm{~B} \cdot \mathrm{FC}_{2} \mathrm{OO}\right]$ formed, so it will not cause the decrease of core permeability.

By $10 \%(\mathrm{OH}) 3 \mathrm{~B}$ - F3C2OOH before and after comparison of permeability of acid and acid treatment of core $12 \% \mathbf{H C l} / \mathbf{3} \% \mathbf{H F}$.Take six blocks of Type II and Type I sandstone for experiment. Core specifications is $8.0 \times 2.5 \mathrm{~cm}$, first washed with $15 \%$ hydrochloric acid about 10 times of the pore volume, and then pump into about 20 times of pore volume treatment fluid, the test temperature is $60^{\circ} \mathrm{C}$. Stop injection for $10 \mathrm{~min}$ before the end of acid injection and determination of the ultimate permeability. The result is shown in Table 2.

Tab.2. core flow experimental data

\begin{tabular}{|l|l|l|l|}
\hline Sandstone & Acid & $\begin{array}{l}\text { Salt water } \\
\text { permeability } \\
\text { before treatment } \\
\left(\times 10^{-3} \mu \mathrm{m}^{2}\right)\end{array}$ & $\begin{array}{l}\text { Salt water } \\
\text { permeability } \\
\text { after treatment } \\
\left(\times 10^{-3} \mu \mathrm{m}^{2}\right)\end{array}$ \\
\hline II & $12 \% \mathrm{HCl} / 3 \% \mathrm{HF}$ & 80 & 115 \\
\hline II & $10 \%(\mathrm{OH})_{3} \mathrm{~B} \cdot \mathrm{F}_{3} \mathrm{C}_{2} \mathrm{OOH}$ & 80 & 105 \\
\hline I & $12 \% \mathrm{HCl} / 3 \% \mathrm{HF}$ & 220 & 1 \\
\hline II & $10 \%(\mathrm{OH})_{3} \mathrm{~B} \cdot \mathrm{F}_{3} \mathrm{C}_{2} \mathrm{OOH}$ & 110 & 210 \\
\hline II & $12 \% \mathrm{HCl} / 3 \% \mathrm{HF}_{3}$ & 15 & 3 \\
\hline II & $10 \%(\mathrm{OH})_{3} \mathrm{~B} \cdot \mathrm{F}_{3} \mathrm{C}_{2} \mathrm{OOH}$ & 2 & 5.5 \\
\hline
\end{tabular}

The serious blocking in outlet tube of core slot. See from the table that only one core permeability is increased after treatment of $12 \% \mathrm{HCl} / 3 \% \mathrm{HF}$, but outlet tube of core slot is seriously blocked. The permeability is increased greatly after treatment of $10 \%\left[(\mathrm{OH})_{3} \mathrm{~B} \cdot \mathrm{F}_{3} \mathrm{C}_{2} \mathrm{OOH}\right]$, that means the effect of $(\mathrm{OH})_{3} \mathrm{~B} \cdot \mathrm{F}_{3} \mathrm{C}_{2} \mathrm{OOH}$ to remove formation plugging is very good, and permeability 
ratio is greater than 1 .

salt water flushing ability of artificial cores after acid treatment of $10 \%(\mathrm{OH})_{3} \mathrm{~B} \cdot \mathrm{F}_{3} \mathrm{C}_{2} \mathrm{OOH}$. Select 16-24 mesh rock particles from type I and II core respectively, mixed with $10 \%$ bentonite, and put it $100 \mathrm{ml}$ into measurer of $2.5 \mathrm{~cm}$ and compact in $0.1 \mathrm{MPa}$, soaking for 48 hours with $(\mathrm{OH})_{3} \mathrm{~B} \cdot \mathrm{F}_{3} \mathrm{C}_{2} \mathrm{OOH}$, then inject $12000 \mathrm{ml} 5 \% \mathrm{KCl}$ of $400 \mathrm{PV}$ with flow rate of $10 \mathrm{ml} / \mathrm{min}$. It does not appear collapsing and breaking of rock particles in the scour process, that means $(\mathrm{OH})_{3} \mathrm{~B} \cdot \mathrm{F}_{3} \mathrm{C}_{2} \mathrm{OOH}$ has good effect on stability of clay and sand consolidation.

\section{Field application and effect analysis}

From January 21,1999 the field application started, 14 wells had been operated until November 30,2000. A good results can be known from the successful rate of construction and increase oil index.

1613 wells of Xinglongtai oil production plant was shutoff for generate of mud and fine sand in January 21,1999 . The reservoir thickness is $21 \mathrm{~m}$, layer number is 7 , oil temperature is $51{ }^{\circ} \mathrm{C}$. Used 15 tons of the agent for unplugging on January 21, and opened the wells on January 25. The daily output of liquid reached $13 \mathrm{~m} 3$, and daily output of oil reached 12 tons. The daily output of oil is to maintain at 3 tons after continuous production for 22 days.

3023 wells of Shuguang oil production plant was shutoff for generate of mud and fine sand in December,1999. The reservoir thickness is $17 \mathrm{~m}$, layer number is 5 , oil temperature is $50{ }^{\circ} \mathrm{C}$. Used 15 tons of the agent for unplugging on December 25, and opened the wells on December 31. The daily average output of oil is 3 tons in January, and 5 tons in February, and 4.6 tons in March. The cumulative oil production is 343 t by the end of May 31 .

\section{Conclusion}

Fluorine complex acid plug removal and sand consolidation agent is triple ionization of acids, and it can used for deep treatment of oil layer. 14 wells which has clay content between $10 \%$ to $30 \%$ were constructed, the effective rate was $85 \%$.

Dissolve ability of clay of fluorine complex acid plug removal and sand consolidation agent is $1000 \mathrm{mg} / 100 \mathrm{ml}$,so it can remove the mud plugging.

The agent can react with quartz sand, then generate a coating of crystalloid fluorine boron and form sandstone skeleton which has capability of resistance to scour upto 400PV.

Permeability ratio of fine powder sand Wells is greater than 1 after unplugging with fluorine complex acid plug removal and sand consolidation agent.

The cumulative incremental oil of this 14 wells is 3864.7 tons, input-output ratio reached 1:2.8, and achieved good economic and social benefits.

\section{References}

[1] MJ ek Naomi des, KJ Noel's kang. The reservoir stimulation.

[2] He Baiping. Oil and gas well sand control. Petroleum exploration and development research institute, 1986-10.

[3] Borchardt, J. K .et al.: SPE12757,1984.

[4] Lindstrom, T.et al.: J.Comlloid and Inteface Sci.,1976, 55, No2. 